\title{
A Case of Acute Pancreatitis in Hemolysis, Elevated Liver Enzymes, and Low Platelets Syndrome
}

\author{
Manuel Pereira Herrera $^{1}$, Joshua B. Oaks ${ }^{2}$, Jeffrey Brensilver ${ }^{1}$ \\ 1. Medicine, Overlook Medical Center, Summit, USA 2. Internal Medicine, Overlook Medical Center, \\ Summit, USA
}

$\square$ Corresponding author: Manuel Pereira Herrera,mph812005@gmail.com

Disclosures can be found in Additional Information at the end of the article

\section{Abstract}

We present a case of hemolysis, elevated liver enzymes, and low platelets (HELLP) syndrome complicated by acute pancreatitis that responded favorably to conservative measures. The microvascular abnormalities and heightened inflammatory state present in HELLP syndrome and severe preeclampsia might be responsible for pancreatic ischemia or cytokine-induced pancreatic damage, which could result in acute pancreatitis.

Categories: Internal Medicine, Obstetrics/Gynecology

Keywords: acute pancreatitis, pregnancy, hellp syndrome, preeclampsia

\section{Introduction}

Acute pancreatitis is a condition with acute inflammation and in some cases necrosis of the pancreas. Etiologies for pancreatitis include biliary disease, alcohol, hypertriglyceridemia, iatrogenic causes (surgical or post-endoscopic retrograde cholangiopancreatography), medications, autoimmunity, trauma, and ischemia [1-3].

Received 06/14/2018

Review began 06/18/2018 Review ended 06/21/2018 Published 06/25/2018

\section{C) Copyright 2018}

Pereira Herrera et al. This is an open access article distributed under the terms of the Creative Commons Attribution License CC-BY 3.0., which permits unrestricted use, distribution, and reproduction in any medium, provided the original author and source are credited.
Hemolysis, elevated liver enzymes, and low platelets (HELLP) syndrome is a condition that belongs to the hypertensive disorders of pregnancy, which include preeclampsia/eclampsia [4]. HELLP syndrome has been associated with severe complications, such as placental abruption, disseminated intravascular coagulation (DIC), pulmonary and cerebral edema, and stroke, among others [1,4-5]. Substantial alterations in the microcirculation have been observed in HELLP syndrome, likely due to microangiopathy and vasospasm [6], the combination of which is thought to contribute to end-organ damage. HELLP syndrome and severe preeclampsia have been reported as etiological factors of pancreatitis [7-11], but this association is yet to be fully accepted. We present a case of pancreatitis in the setting of HELLP syndrome and a review of the literature.

\section{Case Presentation}

A 32-year-old female, gravida 2 para 1 at gestational age of 36 weeks and two days, presented to the Overlook Medical Center at 2:57 am complaining of nausea and contractions, which had started earlier in the night and worsened. Prenatal records were unavailable. Her previous pregnancy was complicated by premature rupture of membranes, and she delivered vaginally a healthy infant at 36 weeks of gestational age. 
During intake, the patient sat upright, appearing uncomfortable, and complained of epigastric pain and vomiting. The physical examination was remarkable for a blood pressure of 202/101 $\mathrm{mmHg}$. Initial laboratory results were significant for the following: white blood cell count (WBC) $13.6 \times 10^{3} / \mu \mathrm{L}$, urine protein of $300 \mathrm{mg} / \mathrm{dL}$, hemoglobin (HGB) $15.6 \mathrm{~g} / \mathrm{dL}$, platelets (PLT) $182 \times 10^{3} / \mu \mathrm{L}$, lipase $200 \mathrm{IU} / \mathrm{L}$, total bilirubin (T bili) $0.2 \mathrm{mg} / \mathrm{dL}$, aspartate transaminase (AST) 56 IU/L, alanine transaminase (ALT) 40 IU/L, alkaline phosphatase (ALP) 162 IU/L, and albumin 2.3 $\mathrm{g} / \mathrm{dL}$.

Upon a diagnosis of severe preeclampsia, the patient was started on intravenous (IV) magnesium sulfate for seizure prophylaxis at $2 \mathrm{~g} / \mathrm{h}$ and was given IV labetalol to control blood pressure. The fetal non-stress test was reactive and category 1 . The patient was scheduled for emergent cesarean section, which was carried out without complications three hours after admission, resulting in the delivery of a vigorous $1.645 \mathrm{~kg}$ male infant, with appearance, pulse, grimace, activity, respiration (APGAR) scores of $8 / 9$ at one and five minutes, respectively. The placenta was delivered complete, and the blood loss during surgery was $680 \mathrm{~mL}$. In the recovery room, the patient continued with high blood pressure values in the 190s/110s mmHg and was given boluses of $10 \mathrm{mg}$ of hydralazine IV in addition to IV labetalol.

Two hours post-operation (post-op), the patient reported severe right upper quadrant pain with worsening nausea and vomiting. Laboratory data at that time revealed up-trending liver enzymes (AST of 1054, ALT of 687, ALP of $134 \mathrm{IU} / \mathrm{L}$ ), a T bili that had risen but was still in the normal range of $0.8 \mathrm{mg} / \mathrm{dL}$, worsening of her hypoalbuminemia at $1.7 \mathrm{~g} / \mathrm{dL}$, anemia of $11.2 \mathrm{~g} / \mathrm{dL}$, thrombocytopenia of $59 \times 10^{3} / \mu \mathrm{L}$, and worsening leukocytosis with neutrophilia $\left(19.9 \times 10^{3} / \mu \mathrm{L}\right.$ and $87.3 \%$ ). Prior to this point, the patient had received $1.6 \mathrm{~L}$ of IV fluids. The international normalized ratio (INR) was slightly elevated at 1.19, and the fibrinogen was decreased at 192 $\mathrm{mg} / \mathrm{dL}$, with fibrin degradation products $\geqslant 20 \mu \mathrm{g} / \mathrm{mL}$. The patient was then transferred to the intensive care unit (ICU) with the diagnosis of HELLP syndrome. A chest x-ray to rule out pulmonary edema reported no significant findings.

Six hours post-op, the patient still complained of right upper quadrant pain and nausea, but these were slightly improving. Her physical exam was remarkable for decreased breath sounds bilaterally at the lung bases and diffuse abdominal tenderness, which was more prominent on the left side. Subsequent laboratory values reported worsening transaminitis with AST of 1332, ALT of 663, ALP of $146 \mathrm{IU} / \mathrm{L}$, increased T bili of $1.1 \mathrm{mg} / \mathrm{dL}, \mathrm{WBC}$ of $20.5 \times 10^{3} / \mu \mathrm{L}$, and worsening PLT of $38 \times 10^{3} / \mu \mathrm{L}$. An elevated lactate dehydrogenase (LDH) of $1881 \mathrm{IU} / \mathrm{L}$ and a decreased haptoglobin of $<8 \mathrm{mg} / \mathrm{dL}$ pointed to a hemolytic process consistent with HELLP syndrome. Although the patient was afebrile, empiric antibiotic coverage with IV cefazolin 2 g every eight hours was initiated out of concern for endometritis given her recent delivery. Her fibrinogen levels had improved, however, to $228 \mathrm{mg} / \mathrm{dL}$. Magnesium levels were monitored, and the magnesium infusion was adjusted accordingly. Blood pressure levels showed signs of better control, with values in the $150 \mathrm{~s} / 105 \mathrm{~s} \mathrm{mmHg}$, and she was maintained on an IV labetalol infusion. A chest x-ray was ordered, and was reported clear. Worsening thrombocytopenia and liver function tests prompted an abdominal computed tomography (CT) scan, which revealed a small volume of complex abdominal and pelvic ascites, mild bilateral pleural effusions and bibasilar atelectasis, and no evidence of subcapsular hematoma, liver, or gallstone pathology. Upon further review of the CT scan, it was felt that the pancreas appeared prominent, which prompted further workup. We include an image of the CT scan below in Figure 1. 


\section{Cureus}

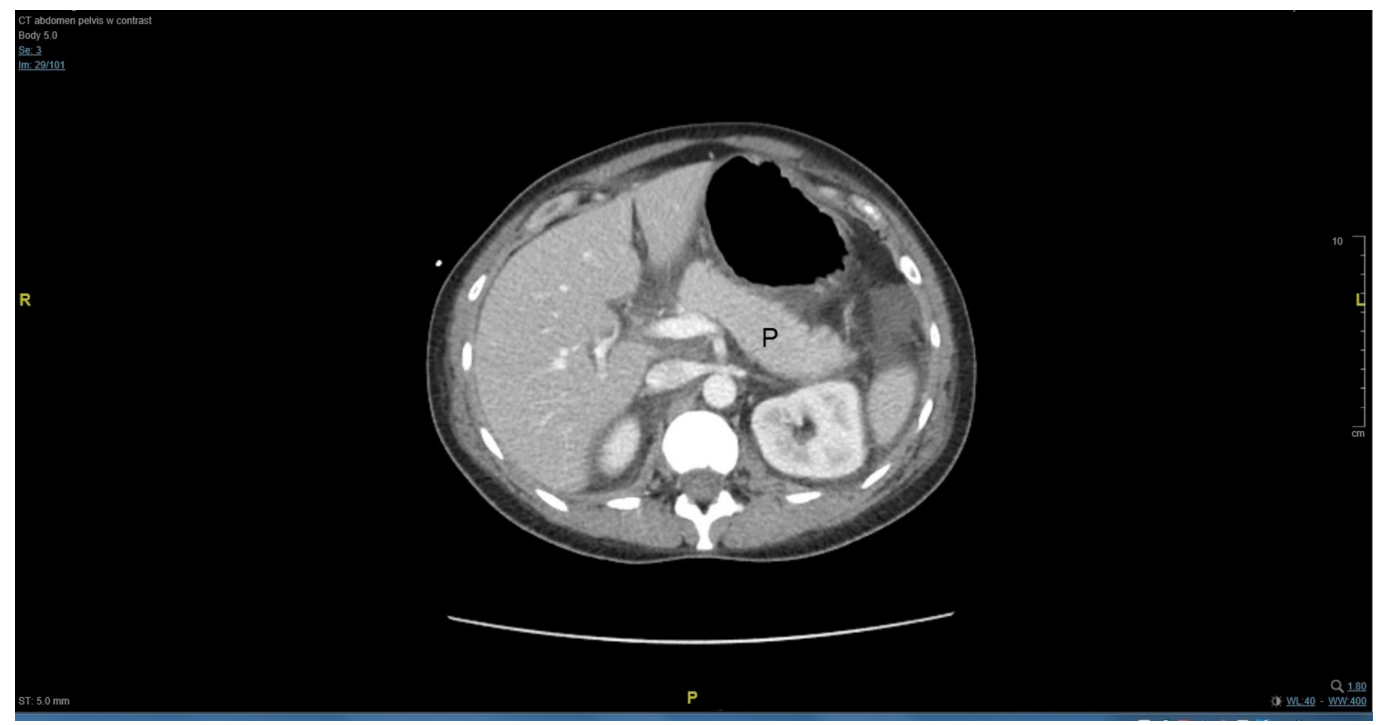

\section{FIGURE 1: Abdominal computed tomography (CT) scan with contrast highlighting the pancreas}

P:pancreas

Twelve hours post-op, the patient had improved blood pressure values in the $130 \mathrm{~s} / 90 \mathrm{~s} \mathrm{mmHg}$. Pancreatitis was confirmed with a lipase of $2365 \mathrm{IU} / \mathrm{L}$, which had risen from $200 \mathrm{IU} / \mathrm{L}$ on admission. Laboratory findings also showed increased lactic acid of $2.9 \mathrm{mmol} / \mathrm{L}$, bicarbonate $\left(\mathrm{HCO}_{3^{-}}\right)$of $22 \mathrm{mEq} / \mathrm{L}$, worsening anemia with HGB of $10.1 \mathrm{~g} / \mathrm{dL}$, down-trending liver enzymes

(AST of 944, ALT of $536 \mathrm{IU} / \mathrm{L}$ ), and improved leukocytosis (WBC of $17.3 \times 10^{3} / \mu \mathrm{L}$ ). The labetalol infusion was discontinued at this point, given her lower blood pressure values. Labetalol, as needed, was ordered to maintain a blood pressure goal of below 150s/110s mmHg.

In the morning of the second day after admission, the patient's blood pressure improved to 145-118 /92-79 $\mathrm{mmHg}$, her right upper quadrant pain was reduced, and her physical exam revealed decreased abdominal tenderness. Laboratory values showed down-trending transaminitis (AST of 573, ALT of 415, ALP of $111 \mathrm{IU} / \mathrm{L}$ ), and decreasing LDH of $1030 \mathrm{IU} / \mathrm{L}$. The anemia and thrombocytopenia had worsened to HGB of $9 \mathrm{~g} / \mathrm{dL}$ and PLT of $36 \times 10^{3} / \mu \mathrm{L}$, with increasing WBC $15.6 \times 10^{3} / \mu \mathrm{L}$. The lipase level had increased to $2509 \mathrm{IU} / \mathrm{L}$ together with the lactic acid $3.9 \mathrm{mmol} / \mathrm{L}$, yet her $\mathrm{HCO}_{3}$ - level remained normal at $23 \mathrm{mEq} / \mathrm{L}$. On the evening of hospital day 2 , she started tolerating clear liquids with only mild nausea. Laboratory results eventually showed normalization of the lipase at $186 \mathrm{IU} / \mathrm{L}$, and her liver enzyme levels continued trending downward, along with trends toward normalization of her other laboratory values.

On the third day after admission, the patient maintained normal blood pressure values (110s/80s mmHg) with oral labetalol. Her abdominal pain continued decreasing and her nausea stopped. She remained on the magnesium sulfate infusion and was transferred from the ICU back to the obstetrics floor. The patient continued to improve on her fourth day, with decreasing liver enzymes (AST of 84, ALT of 113, ALP of 99 IU/L), increasing platelets (PLT 80 $\mathrm{x} 10^{3} / \mu \mathrm{L}$ ), and decreasing WBC at $13.3 \times 10^{3} / \mu \mathrm{L}$, but her HGB dropped to $7.9 \mathrm{~g} / \mathrm{dL}$. The patient was not transfused, as she was hemodynamically stable. Importantly, her creatinine levels remained below $1.1 \mathrm{mg} / \mathrm{dL}$ throughout her hospitalization. The patient was subsequently discharged on the fifth day after admission, with improved HGB of 8.5 g/dL, PLT of 127 
$\mathrm{x} 10^{3} / \mu \mathrm{L}, \mathrm{WBC}$ of $11.7 \times 10^{3} / \mu \mathrm{L}$, and normalization of her transaminitis.

\section{Discussion}

Preeclampsia is defined as a new onset of hypertension in pregnancy $(\geqslant 140 / 90 \mathrm{mmHg}$ after 20 weeks of gestation) together with proteinuria ( $\geqslant 300 \mathrm{mg} /$ day or a protein/creatinine spot urine ratio of at least 0.3 , each measured as $\mathrm{mg} / \mathrm{dL}$ ) [12]. Severe preeclampsia requires the presence of any of the following features: hypertension $\geqslant 160 / 110 \mathrm{~mm} \mathrm{Hg}$, thrombocytopenia $<100,000 / \mu \mathrm{L}$, elevated liver enzymes above twice the upper limit of normal, severe persistent right upper quadrant or epigastric pain, serum creatinine $>1.1 \mathrm{mg} / \mathrm{dL}$ or doubling of serum creatinine, pulmonary edema, or new-onset cerebral or visual disturbances [12]. HELLP syndrome is seen as a particularly serious complication of severe preeclampsia $[1,5]$. There are two principal diagnostic schemes for HELLP syndrome. The Tennessee classification includes the following: 1) evidence of microangiopathic hemolytic anemia by the presence of schistocytes in the blood smear, low serum haptoglobin ( $<1 \mathrm{~g} / \mathrm{L}-<0.4 \mathrm{~g} / \mathrm{L}$ ), and elevated LDH levels; 2) AST $>70 \mathrm{IU} / \mathrm{L}$,

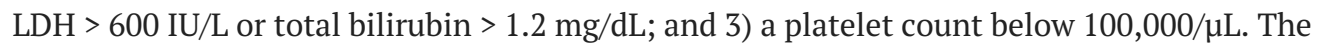
Mississippi classification further stratifies the syndrome based on the platelet nadir [1]. Complete HELLP syndrome is diagnosed when the three components are present, while partial or incomplete HELLP syndrome requires only one or two components. Patients with partial HELLP syndrome tend to develop fewer complications than those with the complete form [5].

The incidence of preeclampsia in pregnancy is reported to be 3\%-5\% [13], while HELLP syndrome complicates about $0.2 \%-0.9 \%$ of all pregnancies [1,5]. HELLP tends to occur in about $10 \%$ to $20 \%$ of cases with severe preeclampsia, and it appears $30 \%$ of the time after delivery [5]. Several mechanisms contribute to the derangements seen in HELLP syndrome. The interaction of maternal immune and vascular endothelial cells with syncytiotrophoblast particles and other placental products triggers an intense inflammatory response, greater than that seen in preeclampsia, which activates the maternal endothelium, promotes platelet aggregation, activates the coagulation cascade, and leads to thrombotic microangiopathy with the resulting hemolytic anemia [1].

The hepatic injury in HELLP is mediated by a placental product, the Fas-ligand (FasL or CD95L), which triggers the synthesis of tumor necrosis factor (TNF) - $\alpha$, resulting in hepatocyte apoptosis and necrosis. The hepatotoxicity of FasL is compounded by ischemic liver damage resulting from restricted portal blood flow, likely related to microangiopathy [1]. Ischemia to important vascular beds may be a consequence of HELLP syndrome and, to a lesser extent, of preeclampsia. Substantial distributive microcirculatory derangements (reduced percentage of small-vessels perfused, reduced functional capillary density, and reduced total capillary density) have been observed in the sublingual microcirculation in patients with preeclampsia compared with healthy pregnant controls. These microvascular alterations were even more severe in HELLP syndrome and were incompletely reversed during the early post-delivery period [6].

Some well-established complications of HELLP syndrome include subcapsular liver hematoma, hepatic rupture, abruptio placentae, DIC with subsequent severe postpartum bleeding, wound hematoma and infection following cesarean section, pulmonary edema, and cerebral infarction, hemorrhage, or edema complicated by brain herniation [1,4-5]. Renal failure, likely secondary to microangiopathy and glomerular endotheliosis, can also be seen in HELLP $[1,5]$. Retinal detachment, vitreal hemorrhage, and cortical blindness are infrequent complications of HELLP to which DIC may contribute [5]. Several cases of acute pancreatitis believed to be caused by preeclampsia/HELLP syndrome have been reported in the literature, lending credence to the opinion that pancreatitis may be a rare complication associated with these pathologies, particularly with HELLP syndrome [7-11]. 
The incidence of pancreatitis in pregnancy has been found to be between $0.02 \%-0.03 \%$, with biliary disease accounting for $67 \%-100 \%$ of all cases [14]. In a recent study, Sang et al. found an incidence rate of $1.23 \%$ of acute pancreatitis in pregnant women with severe preeclampsia [8]. Of those women with severe preeclampsia and pancreatitis, $60 \%$ were additionally found to have HELLP syndrome [8]. The number of reported cases of acute pancreatitis in the context of severe preeclampsia/HELLP syndrome for which no biliary, pharmacological, or other metabolical etiology has been found has been steadily increasing [7-11]. The mechanisms that may trigger an insult to the pancreas could involve 1) ischemia secondary to the microangiopathy exacerbated by vasospasm of the splanchnic circulation; 2) a trigger of pancreatic inflammation related to the increased inflammatory state present in severe preeclampsia/HELLP; or 3) a combination of these two possibilities.

Pancreatic ischemia of even short duration is a well-established factor for the development of acute pancreatitis [2-3]. In cases of ischemia, elevation of pancreatic enzymes may not be present immediately due to the development of massive pancreatic necrosis [3]. Hojo et al. reported a case of acute pancreatitis and cholecystitis associated with HELLP syndrome in which the serum amylase was not elevated and the diagnosis was made by means of CT imaging showing an enlarged pancreas [11]. Vasospasm of the hepatic arteries has also been observed in HELLP syndrome. These facts, together with the evidence for circulatory compromise of several capillary beds in HELLP $[6,11]$, could indicate that ischemia contributes to the pancreatic injury. In our patient, evidence of hypoperfusion shown by increasing lactic acid levels accompanied an increase in the lipase levels. Similarly, a decrease in the lactic acid levels accompanied a decrease in the lipase levels, raising our suspicion that the pancreatic insult may well be related to ischemia.

Elevated levels of inflammation markers such as C-reactive protein, interleukin (IL) -6, and TNF- $\alpha$ are seen in HELLP syndrome. Activation of complement and high levels of von Willebrand factor are also present $[1,15]$. Several cytokines elevated in HELLP are able to activate nuclear factor kappa $\mathrm{b}(\mathrm{NF}-\mathrm{kB})$ [16], and it has been shown that intra-acinar activation of NF-kB can lead to severe acute pancreatitis [17-19]. There is also the possibility that a placental product causing the release of a pancreatotoxic cytokine might be implicated in the pathogenesis of acute pancreatitis in severe preeclampsia/HELLP, mimicking the role of FasL in the liver damage seen in HELLP. Animal studies have reported a novel cytokine, IL-33, as an activator of the proinflammatory pathways in the acinar cells, resulting in acute pancreatitis [20]. Future studies may want to evaluate the role of IL-33 in inducing acute pancreatitis in humans.

\section{Conclusions}

We have presented a case of HELLP syndrome in the post-cesarean section period, complicated by acute pancreatitis. The patient made a full recovery with bowel rest, IV hydration, magnesium sulfate prophylaxis, and careful blood pressure control. It may be important to monitor indicators of tissue hypoperfusion in HELLP syndrome and to rule out possible pancreatitis that may go unnoticed and develop rapidly in these patients.

\section{Additional Information \\ Disclosures}

Human subjects: Consent was obtained by all participants in this study. Conflicts of interest: In compliance with the ICMJE uniform disclosure form, all authors declare the following:

Payment/services info: All authors have declared that no financial support was received from any organization for the submitted work. Financial relationships: All authors have declared that they have no financial relationships at present or within the previous three years with any 
organizations that might have an interest in the submitted work. Other relationships: All authors have declared that there are no other relationships or activities that could appear to have influenced the submitted work.

\section{References}

1. Abildgaard U, Heimdal K: Pathogenesis of the syndrome of hemolysis, elevated liver enzymes, and low platelet count (HELLP): a review. Eur J Obstet Gynecol Reprod Biol. 2013, 166:117123. Accessed: May 10, 2018: 10.1016/j.ejogrb.2012.09.026

2. Kawatani Y, Kurobe H, Nakamura Y, et al.: Acute pancreatitis caused by pancreatic ischemia after TEVAR combined with intentional celiac artery coverage and embolization of the branches of the celiac artery. J Surg Case Rep. 2017, 2:1-4. Accessed: May 10, 2018: 10.1093/jscr/rjx029

3. Gullo LU, Cavicchi LO, Tomassetti PA, Spagnolo CA, Freyrie AN, D'Addato MA: Effects of ischemia on the human pancreas. Gastroenterology. 1996, 111:1033-1038. Accessed: May 10, 2018: 10.1016/S0016-5085(96)70072-0

4. Rao D, Chaudhari NK, Moore RM, Jim B: HELLP syndrome: a diagnostic conundrum with severe complications. BMJ Case Rep. 2016, 1-5. Accessed: May 10, 2018: 10.1136/bcr-2016216802

5. Haram K, Svendsen E, Abildgaard U: The HELLP syndrome: clinical issues and management. A review. BMC Pregnancy Childbirth. 2009, 9:1-8. Accessed: May 10, 2018: 10.1186/1471-23939-8

6. Ospina-Tascón GA, Calvache AJ, Quiñones E, et al.: Microcirculatory blood flow derangements during severe preeclampsia and HELLP syndrome. Pregnancy Hypertens. 2017, 10:124-130. Accessed: May 11, 2018: 10.1016/j.preghy.2017.07.140

7. Swank M, Nageotte M, Hatfield T: Necrotizing pancreatitis associated with severe preeclampsia. Obstet Gynecol. 2012, 120:453-455. Accessed: May 11, 2018: 10.1097/AOG.0b013e31824fc617

8. Sang C, Wang S, Zhang Z, Lu J: Characteristics and outcome of severe preeclampsia/eclampsia concurrent with or complicated by acute pancreatitis: a report of five cases and literature review. J Matern Fetal Neonatal Med. 2017, 2017:1-8. Accessed: May 11, 2018: 10.1080/14767058.2017.1387894

9. Gainder S, Arora P, Saha SC, Kaman L: Acute pancreatitis with eclampsia-preeclampsia syndrome and poor maternal outcome: two case reports and review of literature. Obstet Med. 2015, 8:146-148. Accessed: May 11, 2018: 10.1177/1753495X15585257

10. O’Brien JM, Pursell N, Fumia F: Pancreatic and colonic abscess formation secondary to HELLP syndrome. Case Rep Obstet Gynecol. 2015, 2015:1-4. Accessed: May 1, 2018: $10.1155 / 2015 / 165435$

11. Hojo S, Tsukimori K, Hanaoka M, et al.: Acute pancreatitis and cholecystitis associated with postpartum HELLP syndrome: a case and review. Hypertens Pregnancy. 2007, 26:23-29. Accessed: May 1, 2018: 10.1080/10641950601146491

12. Roberts JM, August PA, Bakris G, et al.: Report of the American College of Obstetricians and Gynecologists' Task Force on hypertension in pregnancy. Obstet Gynecol. 2013, 122:11221131. Accessed: May 14, 2018: 10.1097/01.AOG.0000437382.03963.88

13. Ananth CV, Keyes KM, Wapner RJ: Pre-eclampsia rates in the United States, 1980-2010: ageperiod-cohort analysis. BMJ. 2013, 347:1-9. Accessed: May 14, 2018: 10.1136/bmj.f6564

14. Ramin KD, Ramin SM, Richey SD, Cunningham FG: Acute pancreatitis in pregnancy. Am J Obstet Gynecol. 1995, 173:187-191. Accessed: May 14, 2018: 10.1016/0002-9378(95)90188-4

15. Wallace K, Morris R, Kyle PB, et al.: Hypertension, inflammation and T lymphocytes are increased in a rat model of HELLP syndrome. Hypertens Pregnancy. 2014, 33:41-54. Accessed: May 15, 2018: 10.3109/10641955.2013.835820

16. Lawrence, T: The nuclear factor NF-кB pathway in inflammation . Cold Spring Harb Perspect Biol. 2009, 1:1-11. Accessed: May 15, 2018: 10.1101/cshperspect.a001651

17. Sah RP, Dawra RK, Saluja AK: New insights into the pathogenesis of pancreatitis . Curr Opin Gastroenterol. 2013, 29:523-530. Accessed: May 15, 2018: 10.1097/MOG.0b013e328363e399

18. Sah RP, Dudeja V, Dawra RK, Saluja AK: Cerulein-induced chronic pancreatitis does not require intra-acinar activation of trypsinogen in mice. Gastroenterology. 2013, 144:1076- 


\section{Cureus}

1085. Accessed: May 15, 2018: 10.1053/j.gastro.2013.01.041

19. Szatmary P, Gukovsky I: The role of cytokines and inflammation in the genesis of experimental pancreatitis. Pancreapedia: Exocrine Pancreas Knowledge Base. 2016, 2016:115. Accessed: May 16, 2018: 10.3998/panc.2016.29

20. Kempuraj D, Twait EC, Williard DE, Yuan Z, Meyerholz DK, Samuel I: The novel cytokine interleukin-33 activates acinar cell proinflammatory pathways and induces acute pancreatic inflammation in mice. PLoS One. 2013, 8:1-14. Accessed: May 16, 2018:

10.1371/journal.pone.0056866 